\title{
The Role of Pelvic Floor Muscles Exercises with Biofeedback as Adjuvant Treatment in Men with Erectile Dysfunction
}

\author{
Guido O Vianney ${ }^{1}$, Ratna D Haryadi ${ }^{1}$, Rwahita Satyawati ${ }^{1}$, Onny P Sono ${ }^{2}$ \\ 1 Departement of Physical Medicine and Rehabilitation, Dr. Soetomo Hospital - Faculty of Medicine \\ Airlangga University, Surabaya, Indonesia. \\ 2 Andrology Clinic, Dr. Soetomo Hospital, Surabaya, Indonesia.
}

\begin{abstract}
Objective: To evaluate the efficacy of pelvic floor muscle exercise programs for men with erectile dysfunction problems.

Methods: A randomized controlled group designed study. Sixteen men with erectile dysfunction who had undergone pharmacological treatment from the Andrology Clinic and were referred to the Physical Medicine and Rehabilitation Department Dr. Soetomo Hospital were divided into 2 groups. The first group was treated with pelvic floor muscle exercises for 12 weeks, while the second group acted as control.
\end{abstract}

The parameters of this study were evaluated in weeks 4,8 and 12 . This consisted of an evaluation of pelvic floor muscle strength, which was performed by digital anal assessment, and pressure biofeedback Myomed 932. The evaluation of erectile function was based on the IIEF-5 (International Index of Erectile Function - 5) questionnaire and the EHS (Erectile Hardness Score).

Results: An increase in the maximum contraction of pelvic floor muscles was seen in the intervention group after 8 weeks of treatment $(\mathrm{p}=0.011)$. Six subjects in the intervention group (75\%) gained a normal anal strength based on digital anal assessment at the end of study.

The IIEF- 5 score of the intervention group improved after 8 weeks of treatment $(\mathrm{p}=0.012)$. Three subjects (37.5\%) in the intervention group got a maximum hardness score and 4 subjects (50\%) gained an improvement of the hardness score.

Conclusion: Comparing of the results of the protocol reported here shows that pelvic floor muscle exercises improve erectile function in men with erectile dysfunction problems.

Keywords: pelvic floor muscle exercises, biofeedback, erectile dysfunction

\section{INTRODUCTION}

Erectile dysfunction (ED) was defined as the inability to achieve or maintain a sufficient

Received in March 2014 and accepted for publication in April 2014.

Correspondence detail: Guido O Vianney.guido_oktav@ yahoo.com erection for satisfactory sexual performance for both partners. ${ }^{1} \mathrm{ED}$ is common and affects more than half of men aged over 40 years and increases dramatically in men over 50 years. ${ }^{2}$ The prevalence of ED in the USA reached 35\% for mild to moderate grade. ${ }^{3-4}$ In 2010, 109 patients visited the Andrology Clinic of Dr. Soetomo Hospital, with 30 new cases.

Different treatment regimens are available for ED including psychotherapy, 
oral pharmacological agents, injections, vacuum devices and surgery. ${ }^{5-6}$ The pelvic floor muscle (PFM) exercises have been proven to be effective in restoring bowel and bladder function $^{7-8}$, but the role of PFM exercises in the treatment of ED is still open for debate. It was stated that the contraction of ischiocavernosus and bulbocavernosus muscles result in an increase of intracavernosus pressure and affects penile rigidity. ${ }^{6,}$ 9-11 There was no consensus about the protocol of PFM exercises in treating ED problems until now., 11-12

Our study was a pilot study in The Department of Physical Medicine and Rehabilitation Dr. Soetomo Hospital to evaluate the efficacy of PFM exercises for men with ED problems.

\section{METHODS}

\section{Ethics approval}

Approval was obtained from Dr. Soetomo Hospital Surabaya Ethics Committee.

\section{Participants}

Men who had experienced ED for 6 months or more were referred to The Department of Physical Medicine and Rehabilitation by Andrology Clinic Dr. Soetomo Hospital. Those men with urological congenital abnormalities, neuromuscular problems that affect pelvic floor muscle strength, previous trauma or surgery that affects erectile function, psychogenic cause of erectile dysfunction, uncontrolled diabetes mellitus, severe hypertension and dyslipidemia, andropause patients and severe obesity were excluded from the trial.

\section{Randomization and recruitment}

The participants who fulfilled the inclusion criteria and were enrolled into the trial were randomized into either intervention or control group by a block randomization sampling method. The first group were treated with PFM exercises, while the second group acted as control.

\section{Intervention}

All participants had undergone treatment from the Andrology Clinic Dr. Soetomo Hospital. Men in the intervention group were also given a protocol of PFM exercises, 3 times a day for 12 weeks. Once a week, they performed exercises with pressure biofeedback Myomed 932 in the clinic. They were instructed to do 10 repetitions of 6 seconds maximal contraction with 12 seconds of rest period, and then 4 repetitions of fast and strong contractions, followed by 18 seconds of relaxation. Men in the control group only received pharmacological treatment from the Andrology Clinic.

\section{Outcome measures}

The primary outcome measure was the strength of pelvic floor muscles, performed by digital anal assessment and pressure biofeedback Myomed 932. The secondary outcome was erectile function, based on The International Index of Erectile Function-5 (IIEF-5) and The Erectile Hardness Score (EHS), which were self-completed by the participants. All parameters were evaluated at the baseline, after 4 weeks, 8 weeks and 12 weeks.

\section{Data analysis}

All analysis was conducted using SPSS. Statistical calculations were performed using an independent samples t-test for numerical data and the Wilcoxon signed-ranked test for ordinal data, with $\mathrm{p}<0.05$ considered significant.

\section{RESULTS}

\section{Baseline characteristics of subjects}

Of total 16 participants, 8 were randomised into intervention and 8 into control group. 


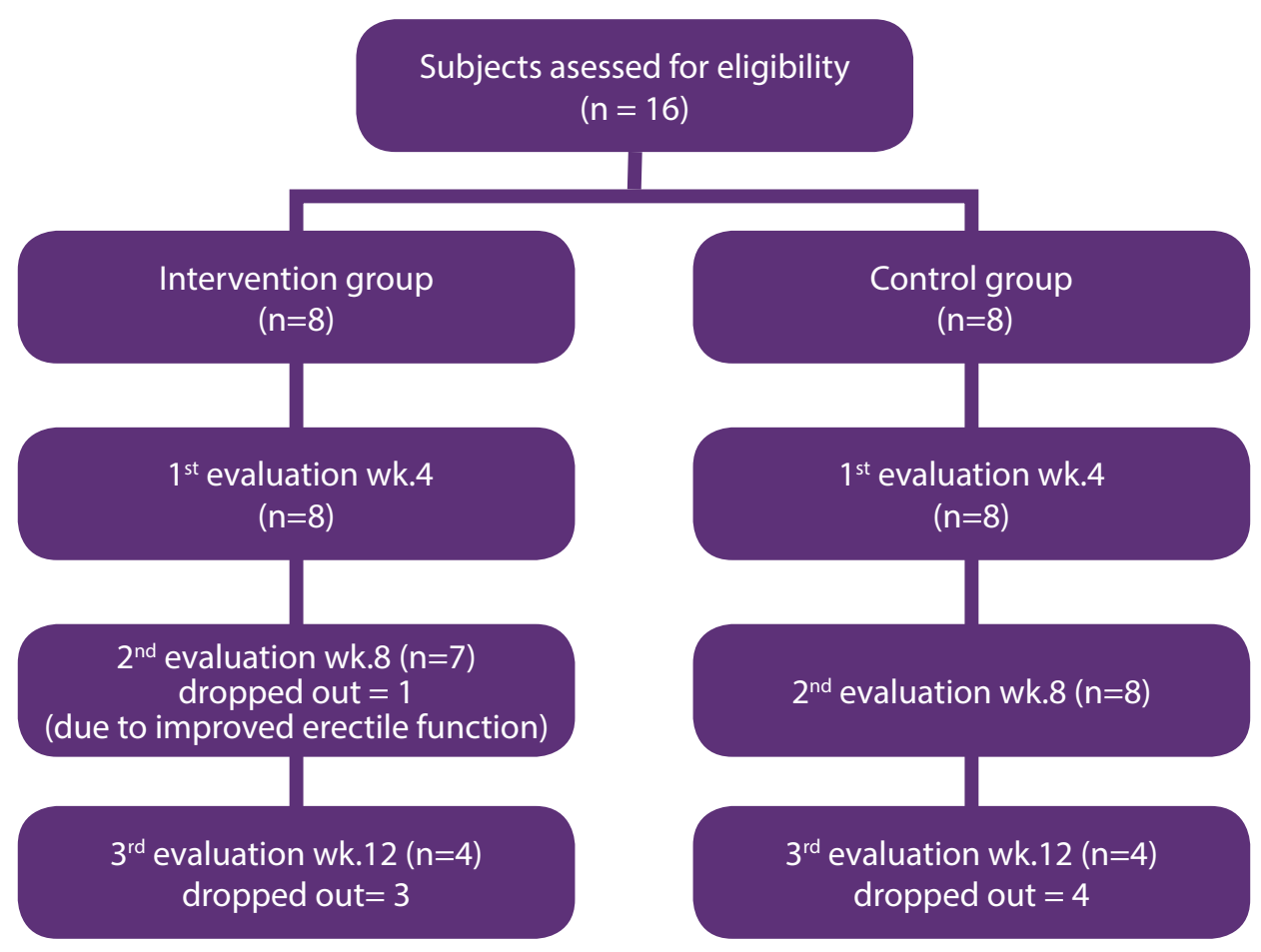

Figure 1. Algorithm of the Study

All participants followed the evaluation after 4 weeks of treatment. One participant of the intervention group withdrew following improved erectile function after 8 weeks. The data about erectile function of this participant was collected from the Andrology clinic and confirmed by a phone call. Three participants in the intervention group and 4 participants in the control group withdrew after 12 weeks due to various reasons. Fifty percent of participants did not remain in the trial for the intended duration. Because of the lack of participants who still remained in the trial after 12 weeks, we did the statistical calculation up until the second evaluation only.

The baseline characteristics of both groups were shown in table 1. There was no significant differences in the baseline characteristics between the intervention and control group except the PFM strength based on digital anal assessment. The mean age of subjects in the intervention group was older than that in the control group, but there was no significant difference between them. Most of the subjects in the intervention group had a mild-moderate degree of ED. 
Table 1. Baseline Characteristic of Participants

\begin{tabular}{lccc}
\hline \multicolumn{1}{c}{ Variables } & $\begin{array}{c}\text { Intervention group } \\
(\mathbf{n = 8})\end{array}$ & $\begin{array}{c}\text { Control group } \\
(\mathbf{n = 8})\end{array}$ & p-value \\
\hline Age (year) & $60.50 \pm 8.96$ & $52.86 \pm 8.89$ & 0.110 \\
Body weight (kg) & $64.00 \pm 7.69$ & $69.50 \pm 10.54$ & 0.253 \\
Height (cm) & $163.13 \pm 5.89$ & $164.25 \pm 4.92$ & 0.685 \\
Body Mass Index (kg/m2) & $24.05 \pm 2.72$ & $25.69 \pm 3.19$ & 0.286 \\
Duration of ED (year) & $2.56 \pm 3.04$ & $3.31 \pm 2.91$ & 0.622 \\
Severity of ED & $0 / 7 / 1$ & $2 / 4 / 2$ & 0.700 \\
(Mild/ Mild-moderate/ moderate) & $(0 \% / 87.5 \% / 2.5 \%)$ & $(25 \% / 50 \% / 25 \%)$ & 1.000 \\
Hipertension (Yes/No) & $3 / 5$ & $3 / 5$ & 0.614 \\
Diabetes melitus (Yes/No) & $(37.5 \% / 62.5 \%)$ & $(37.5 \% / 62.5 \%)$ & $3 / 5$ \\
Digital anal assessment & $4 / 4$ & $(37.5 \% / 62.5 \%)$ & $0.044 \dagger$ \\
PFM minimal contraction (CmH2O) & $(50 \% / 50 \%)$ & $4(4-5)$ & 0.271 \\
PFM maximal contraction (CmH2O) & $4(3-4)$ & $50.37 \pm 16.94$ & 0.371 \\
The IIEF-5 score & $40.76 \pm 16.66$ & $196.63 \pm 79.09$ & 1.000 \\
The EHS & $231.00 \pm 69.27$ & $14.25 \pm 3.69$ & 0.872 \\
\hline
\end{tabular}

note: value is mean \pm standard deviation or median (range of value)

$\dagger p$ considered significant $(\mathrm{p}<0.05)$

\section{Pelvic floor muscle strength}

The evaluation of PFM strength based on digital anal assessment is shown in table 2 . There was a significant difference between the intervention and the control group for the baseline of digital anal assessment $(\mathrm{p}=0.044)$. Both groups had the same median value (4) but the control group had a greater range, between 4-5, while the intervention group was between 3-4. The intervention group gained a significant increase of digital anal assessment after 8 weeks of treatment $(\mathrm{p}=0.014)$ with 5 subjects $(62.5 \%)$ gaining a maximum anal strength (5). There was no significant increase of digital anal assessment value in the control group.

Table 2. Evaluation of PFM Strength Based on Digital Anal Assessment

\begin{tabular}{lcccccc}
\hline & Baseline & $\begin{array}{c}\text { Evaluation } \\
\text { week-4 }\end{array}$ & $\begin{array}{c}\text { Evaluation } \\
\text { week-8 }\end{array}$ & $\begin{array}{c}\text { p-value } \\
\text { Baseline vs } \\
\text { Evaluation } \\
\text { week-4 }\end{array}$ & $\begin{array}{c}\text { p-value } \\
\text { Baseline vs } \\
\text { Evaluation } \\
\text { week-8 }\end{array}$ & $\begin{array}{c}\text { p-value } \\
\text { Evaluation } \\
\text { week-4 vs } \\
\text { week-8 }\end{array}$ \\
\hline $\begin{array}{c}\text { Intervention } \\
\text { Group }\end{array}$ & $\begin{array}{c}4(3-4) \\
(\mathrm{n}=8)\end{array}$ & $\begin{array}{c}4(3-4) \\
(\mathrm{n}=8)\end{array}$ & $\begin{array}{c}5(4-5) \\
(\mathrm{n}=7)\end{array}$ & 0.157 & $0.014 \dagger$ & $0.046 \dagger$ \\
Control Group & $\begin{array}{c}4(4-5) \\
(\mathrm{n}=8)\end{array}$ & $\begin{array}{c}4(4-5) \\
(\mathrm{n}=8)\end{array}$ & $\begin{array}{c}4(4-5) \\
(\mathrm{n}=8)\end{array}$ & 1.000 & 1.000 & 1.000 \\
$\begin{array}{c}\text { p-value } \\
\text { Intervention vs } \\
\text { Control Group }\end{array}$ & $0.044 \dagger$ & 0.424 & 0.204 & & & \\
\hline
\end{tabular}

note: value is median (range of value)

$\dagger p$ considered significant $(p<0.05)$ 
The evaluation of PFM strength based on maximal contraction is shown in table 3 . The intervention group showed an increase of PFM maximal contraction, greater than that in the control group after 8 weeks of treatment $(p=0.011)$. It was noted that both groups had a high minimal contraction of around 40-50 CmH20 in every evaluation. Two participants (25\%) in the control group could not reach 100 $\mathrm{CmH} 20$ in contracting their pelvic floor muscles

Table 3. Evaluation of PFM Strength Based on Maximal Contraction

\begin{tabular}{|c|c|c|c|c|c|c|}
\hline & Baseline & $\begin{array}{c}\text { Evaluation } \\
\text { week-4 }\end{array}$ & $\begin{array}{c}\text { Evaluation } \\
\text { week-8 }\end{array}$ & $\begin{array}{c}\text { p-value } \\
\text { Baseline vs } \\
\text { Evaluation } \\
\text { week-4 }\end{array}$ & $\begin{array}{c}\text { p-value } \\
\text { Baseline vs } \\
\text { Evaluation } \\
\text { week-8 }\end{array}$ & $\begin{array}{c}\text { p-value } \\
\text { Evaluation } \\
\text { week-4 vs } \\
\text { week-8 }\end{array}$ \\
\hline $\begin{array}{l}\text { Intervention } \\
\text { Group }\end{array}$ & $\begin{array}{c}231.00 \pm 69.27 \\
(n=8)\end{array}$ & $\begin{array}{c}253.38 \pm 55.47 \\
(n=8)\end{array}$ & $\begin{array}{c}290.29 \pm 24.76 \\
(n=7)\end{array}$ & 0.469 & $0.019 \dagger$ & 0.090 \\
\hline Control Group & $\begin{array}{c}196.63 \pm 79.09 \\
(n=8)\end{array}$ & $\begin{array}{c}205.38 \pm 85.51 \\
(n=8)\end{array}$ & $\begin{array}{c}192.75 \pm 83.87 \\
(n=8)\end{array}$ & 0.746 & 0.880 & 0.630 \\
\hline $\begin{array}{c}\text { p-value } \\
\text { Intervention vs } \\
\text { Control Group }\end{array}$ & 0.371 & 0.204 & $0.011 \dagger$ & & & \\
\hline
\end{tabular}

note: value is mean \pm standard deviation

$\uparrow \mathrm{p}$ considered significant $(\mathrm{p}<0.05)$

\section{Erectile function}

The evaluation of erectile function based on the IIEF-5 score is shown in table 4. After 8 weeks, both groups showed an increase of IIEF-5 score, but the intervention group scored significantly higher $(\mathrm{p}=0.012)$. Three participants $(37.5 \%)$ made an improvement and 4 participants (50\%) gained normal erectile function based on the IIEF-5 score.

Table 4. The Erectile Function Based on the IIEF-5 Score

\begin{tabular}{|c|c|c|c|c|c|c|}
\hline & Baseline & $\begin{array}{c}\text { Evaluation } \\
\text { week-4 }\end{array}$ & $\begin{array}{c}\text { Evaluation } \\
\text { week-8 }\end{array}$ & $\begin{array}{c}\text { p-value } \\
\text { Baseline vs } \\
\text { Evaluation } \\
\text { week-4 }\end{array}$ & $\begin{array}{c}\text { p-value } \\
\text { Baseline vs } \\
\text { Evaluation } \\
\text { week-8 }\end{array}$ & $\begin{array}{c}\text { p-value } \\
\text { Evaluation } \\
\text { week-4 vs } \\
\text { week-8 }\end{array}$ \\
\hline $\begin{array}{c}\text { Intervention } \\
\text { Group }\end{array}$ & $\begin{array}{c}14.25 \pm 2.05 \\
(n=8)\end{array}$ & $\begin{array}{c}17.38 \pm 3.46 \\
(n=8)\end{array}$ & $\begin{array}{c}19.50 \pm 4.34 \\
(n=8)\end{array}$ & $0.016 \dagger$ & $0.005 \dagger$ & $0.028 \dagger$ \\
\hline Control Group & $\begin{array}{c}14.25 \pm 3.69 \\
(n=8)\end{array}$ & $\begin{array}{c}16.00 \pm 4.24 \\
(n=8)\end{array}$ & $\begin{array}{c}15.88 \pm 5.06 \\
(n=8)\end{array}$ & 0.122 & 0.189 & 0.836 \\
\hline $\begin{array}{l}\text { p-value } \\
\text { Intervention vs } \\
\text { Control Group }\end{array}$ & 1.000 & 0.489 & $0.012 \dagger$ & & & \\
\hline
\end{tabular}

note: value is mean \pm standard deviation

$\uparrow \mathrm{p}$ considered significant $(\mathrm{p}<0.05)$

The evaluation of erectile function based on the EHS is shown in table 5. There was no significant difference between the two groups based on EHS. The intervention group showed a significant increase in the hardness scale after 4 weeks $(p=0.046)$ and after 8 weeks $(p=0.014)$, but the control group showed no significant increase.
Three participants $(37.5 \%)$ gained maximal score (4) and 4 participants (50\%) made an improvement. The first improvement of erectile function was reported within 2-4 weeks after the initial treatment (harder erection and experienced nocturnal erection again). 
Table 5. The Erectile Function Based on the EHS

\begin{tabular}{|c|c|c|c|c|c|c|}
\hline & Baseline & $\begin{array}{c}\text { Evaluation } \\
\text { week-4 }\end{array}$ & $\begin{array}{c}\text { Evaluation } \\
\text { week-8 }\end{array}$ & $\begin{array}{c}\text { p-value } \\
\text { Baseline vs } \\
\text { Evaluation } \\
\text { week-4 }\end{array}$ & $\begin{array}{c}\text { p-value } \\
\text { Baseline vs } \\
\text { Evaluation } \\
\text { week-8 }\end{array}$ & $\begin{array}{c}\text { p-value } \\
\text { Evaluation } \\
\text { week-4 vs } \\
\text { week-8 }\end{array}$ \\
\hline $\begin{array}{l}\text { Intervention } \\
\text { Group }\end{array}$ & $\begin{array}{l}2.25 \\
(1-3) \\
(n=8)\end{array}$ & $\begin{array}{l}2.75 \\
(2-4) \\
(n=8)\end{array}$ & $\begin{array}{c}3 \\
(2-4) \\
(n=8)\end{array}$ & $0.046 \dagger$ & $0.014 \dagger$ & 0.063 \\
\hline Control Group & $\begin{array}{c}2.25 \\
(1-3.5) \\
(n=8)\end{array}$ & $\begin{array}{c}2.50 \\
(1.5-3.5) \\
(n=8)\end{array}$ & $\begin{array}{c}2,25 \\
(1.5-3.5) \\
(n=8)\end{array}$ & 0.276 & 0.461 & 1.000 \\
\hline $\begin{array}{c}\mathrm{p} \text {-value } \\
\text { Intervention vs } \\
\text { Control Group }\end{array}$ & 0.872 & 0.553 & 0.108 & & & \\
\hline
\end{tabular}

note: value is median (range of value)

$\dagger p$ considered significant $(\mathrm{p}<0.05)$

\section{DISCUSSION}

\section{The pelvic floor muscle exercises protocol}

Many protocols have been used in PFM rehabilitation but there was no consensus about the optimal technique and duration of PFM exercises. ${ }^{6}{ }^{13}$ The protocol of PFM exercises used in this study was the common protocol in our department and it demonstrated to be effective in restoring PFM function, i.e. study of men with post TUR due to benign prostate hyperplasia $(\mathrm{p}=0.003) .{ }^{14}$ Our protocol consisted of 14 contractions in each session, 3 times a day for 12 weeks. It has a smaller number of PFM contractions and a shorter period than other protocol studies, i.e. in a study by Van Kampen that suggested 30 contractions each day for 16 weeks. We did hope that it could reduce the number of drop-outs in our study.

\section{Summary of main findings}

There was a significant difference between the intervention and the control group for baseline value of digital anal assessment $(\mathrm{p}=0.044)$. These findings may be due to the fact that the range of the value of digital anal assessment were already different between the two groups. Besides that, the measurement of digital anal assessment parameters were not done by a blind assessor, which could make the assessor biased. The intervention group gained a significant increase of digital anal assessment after 4 weeks of treatment $(p=0.046)$ and a greater increase after 8 weeks $(\mathrm{p}=0.014)$ with 5 subjects gaining a maximal anal strength (5).

Pressure biofeedback Myomed 932 showed a significant increase of pelvic floor muscles maximal contraction in the intervention group, greater than that in the control group $(\mathrm{p}=0.011)$. These results were consistent with other trials that evaluate the effect of pelvic floor muscle exercises. ${ }^{10,15}$

Both groups showed a relative spasm condition of pelvic floor muscles with the resting tone around $40-50 \mathrm{CmH} 2 \mathrm{O}$. These condititons might be due to the chronic dysfunction of pelvic floor muscles in the participants.7 Two subjects in the control group (25\%) failed to achieve $100 \mathrm{CmH} 2 \mathrm{O}$ in maximal contraction because they found it difficult to contract the pelvic floor muscles as instructed. These findings supported the theory that men with pelvic floor muscle dysfunction, usually find it difficult to contract the muscles. ${ }^{16-18}$

The intervention group scored significantly better than the control group in erectile function based on the IIEF-5 $(\mathrm{p}=0.012)$ after 8 weeks of treatment, with a 5.25 point increase. Four participants (50\%) gained normal erectile function. These results were in line with a trial by Dorey, that showed a significant increase of the IIEF score after 12 weeks of treatment. ${ }^{10}$

Even though there was no significant difference in erectile function based on the EHS, the intervention group showed a significant 
increase on the hardness scale after 4 weeks $(\mathrm{p}=0.046)$ and after 8 weeks of treatment $(\mathrm{p}=0.014)$, but the control group showed no significant increase. Three participants (37.5\%) gained a maximal score (4) and 4 participants (50\%) made an improvement.

The first improvement of erectile function was reported within 2-4 weeks after the initial treatment (harder erection and experienced nocturnal erection again). These results were similar with the results of other trials, that first showed an improvement 1-6 weeks after the beginning of treatment. ${ }^{10,15}$ One subject in the intervention group (12.5\%) failed to achieve an improvement in erectile function. It might be due to coronary heart disease as a comorbidity factor. $^{2}$ Dorey, in his trial, reported that participants who failed to improve reported possible reasons such as, cardiovascular problems, diabetes mellitus, alcoholism etc. ${ }^{10}$

The participants also reported subjective findings, such as an increase in duration of erection, increase of libido and better orgasm. Other trials also reported the increase of orgasm quality with no significant improvement in libido.10 The mechanism behind them through PFM may be related with self-familiarity and body awareness, which may improve self confidence and sense of control. ${ }^{7}$

The participants reported other improvements beside erectile function. Five subjects in the intervention group (62.5\%) who complained of bladder and bowel disturbances reported an improvement after 4-8 weeks of exercises. These findings were similar with a trial by Anthonius that PFM exercises improved bladder function 14 and supported the theory that sexual dysfunction is comorbid with symptoms associated with pelvic floor and urinary dysfunction in men. ${ }^{7}$

The high rate of withdrawal reported in this study is in line with the similar trials. This condition might be correlated with a lack of commitment involved in performing daily exercises. ${ }^{10}$

The age, the duration and severity of erectile dysfunction and the kind of pharmacological therapy were not predictors of the results of therapy in this study.

\section{Limitation of this study}

This study was limited for several reasons. The baseline characteristics of the digital anal assessment was not homogenous between the intervention and the control group. All subjects received different pharmacological treatments from the Andrology Clinic. We were not able to control these conditions nor to control the motivation of the participants to continue the trial. All evaluations were not done by a blind assessor, which allowed assessment bias. Another limitation was the use of a nonvalidated Indonesian version of the IIEF-5.

\section{CONCLUSION}

Pelvic floor muscle exercises could be considered as adjuvant treatment for men with ED problems. It is a non-invasive method, easy to perform, painless and inexpensive. Evidence has shown the efficacy of these exercises for men with erectile dysfunction problems. Not all men with erectile dysfunction problems may be suitable for PFM exercises. Based on this study, men with mild to moderate erectile dysfunction with less comorbidity factors may get more benefit from PFM exercises.

To obtain an optimal result, pelvic floor muscle exercises should be properly taught and practised for at least 8 weeks. A maintenance programme may then be practised for life, but the long-lasting effect of the exercises were not studied in this trial. Further trials with a better methodology are needed to evaluate the longlasting effect of PFM exercises on ED.

\section{REFERENCES}

1. National Institute of Health. Impotence. NIH Consensus Development Panel on Impotence. Am Med Assoc. 1993;270:83 -90 .

2. Hood S, Kirby M. Review: Risk factor assessment of erectile dysfunction. British Journal of Diabetes \& Vascular Disease. 2004;4:157-61.

3. Kubin M, Wagner G, Fugl-Meyer A. Epidemiology of erectile dysfunction. 
International Journal of Impotence Research. 2003;15:63-71.

4. Shabsigh R. Epidemiology of Erectile Dysfunction. In: Mulcahy JJ, editor. Male Sexual Function: A Guide to Clinical Management. 2nd ed. New Jersey: Humana Press; 2006. p. 47.

5. Fazio L, Brock G. Erectile Dysfunction: Management Update. CMAJ 2004;170(9):1429-37.

6. Dorey G. Pelvic Dysfunction in Men: Diagnosis and Treatment of Male Incontinence and Erectile Dysfunction. Chichester: Jon Wiley \& Sons; 2006.

7. Rosenbaum TY. Pelvic Floor Involvement in Male and Female Sexual Dysfunction and the Role of Pelvic Floor Rehabilitation in Treatment: A Literature Review. J Sex Med 2007;4:4-13.

8. Nugteren HM, Schultz WCMW, Driel MFv. Physical therapy for premature ejaculation, erectile dysfunction and chronic pelvic pain syndrome. Journal Compilation BJU International 2009. --> volume, nomor, halaman jurnal?

9. Colpi G, Negri L, Nappi R, Chinea B. Perineal floor efficiency in sexually potent and impotent men. International Journal of Impotence Research. 1999;11:153-7.

10. Dorey G, Speakman M, Feneley $\mathrm{R}$, Swinkels A, Dunn C, Ewings $\mathrm{P}$. Randomised controlled trial of pelvic floor muscle exercises and manometric biofeedback for erectile dysfunction. British Journal of General Practice. 2004;54:819-25.

11. Persu C, Cauni V, Gutue S, Albu ES, Geavlete VJ. Diagnosis and treatment of erectile dysfunction - a practical update. Journal of Medicine and Life 2009 October-December 2(4):394-400

12. Rosenbaum TY. The role of physiotherapy in sexual health: Is it evidence-based? Journal of the Association of Chartered Physiotherapists in Women's Health. 2006;99:1-5.

13. Russell B, Brubaker L. Muscle Function and Ageing. In: Baessler K, Schussler B, editors. Pelvic Floor Re-education. 2nd ed. London: Springer; 2008. p. 49-60.

14. Anthonius M. Pengaruh Latihan Otot Dasar Panggul Dengan Penambahan Sarana Biofeedback Terhadap Penderita Pasca Operasi Hiperplasia Prostat Jinak Dengan Metode TUR. Surabaya: Dept / SMF Rehabilitasi Medik - RSUD Dr. Soetomo FK Unair; 2003. --> thesis atau disertasi?

15. Kampen MV, Weerdt WD, Claes H, Feys H, Maeyer MD, Poppel HV. Treatment of Erectile Dysfunction by Perineal Exercise, Electromyographic Biofeedback, and Electrical Stimulation. Physical Therapy. 2003;83(6):536-43.

16. Esch FH. Examination and Treatment of Pelvic Floor Dysfunction. Myofeedback Therapy book. Groningen: Enraf-Nonius; 2004. p. 36-60.

17. Laycock J. Assessment and treatment of pelvic floor dysfunction. Bradford UK: University of Bradford; 1992.

18. Wolf SL. Biofeedback. In: Gonzalez E, Myers SJ, editors. Downey and Darling's Physiological Basic of Rehabilitation Medicine. 3rd ed. Boston: ButterwothHeinemann; 2001. p. 747-759. 